\title{
Detection of Mycobacterium avium subsp. paratuberculosis from cattle and buffaloes in Egypt using traditional culture, serological and molecular based methods
}

\author{
G. S. Abdellrazeq, M. M. Elnaggar, S. A. Khaliel and A. E. Gamal-Eldin
}

Department of Microbiology,

Faculty of Veterinary Medicine, Alexandria University, Edfina, Rosetta-line, P. O. Box: 22758, Egypt.

Corresponding author: Gaber Abdellrazeq, email: gaber.abdellatif@alexu.edu.eg

MME: mahmoud.elnaggar@alexu.edu.eg, SAK: khaliel1@yahoo.com, AEG: dr_asmaa9518@yahoo.com

Received: 03-05-2014, Revised: 02-07-2014, Accepted: 10-07-2014, Published online: 11-08-2014

doi: 10.14202/vetworld.2014.586-593 How to cite this article: Abdellrazeq GS, Elnaggar MM, Khaliel SA and Gamal-Eldin AE (2014) Detection of Mycobacterium avium subsp. paratuberculosis from cattle and buffaloes in Egypt using traditional culture, serological and molecular based methods, Veterinary World 7(8): 586-593.

\begin{abstract}
Background: Johne's disease (JD) caused by Mycobacterium avium subsp. paratuberculosis (MAP) represents a real threat to the agriculture and dairy food industries and believed to be a potential public health problem. Signs of infection in ruminant include weight loss, diarrhea, decreased milk production, and eventually death. The definition of an infected animal based either on the presence of anti-MAP antibodies, or positive bacterial culture. No treatment for the disease exists and controlling the disease is difficult due to its long latent period. JD is a worldwide problem and multiple studies in many countries have been carried out to determine the prevalence of MAP infections. Although some primary non intensive studies confirm presence of JD in Egypt, the disease is currently neglected by the official Egyptian veterinary agencies. There is no official data, no national control program, and no used vaccine.
\end{abstract}

Aim: This study aimed to evaluate three conventional diagnostic methods for MAP under the Egyptian circumstances with a general aim to determine the appropriate strategy to develop a JD control program. These methods were pooled fecal culture, humoral response and insertion sequence IS 900 targets polymerase chain reaction (IS 900 PCR).

Materials and Methods: Fecal and serum samples (500 each) were collected from Holstein-Friesian cattle and buffaloes housed in five Egyptian governorates. Fecal samples were examined for MAP on the basis of a strategic pooling procedure and performed on Herrold's Egg Yolk Agar Medium (HEYM). Smears were prepared from developed colonies and stained using a Ziehl-Neelsen (ZN) technique. The identity of developed colonies was further confirmed by PCR analysis of IS900 sequence. Sera from both culture-positive and culture-negative animals were evaluated individually for humoral response.

Results: Out of 50 pooled specimens, $34(68 \%)$ fecal cultures were positive for MAP. Serum positive samples of culturepositive animals were $63 / 340(18.5 \%)$. No serum positive were detected in the samples from culture-negative animals. DNA extractions from colonies of 34 culture-positive pooled samples were tested with the PCR targeted to IS900 and revealed 18 isolates $(52.94 \%)$ were positive.

Conclusion: The present study has succeeded in isolating and identifying of MAP from Egyptian cattle and buffaloes in five governorates. The results confirm the epizoology of JD in Egypt and encourage the decision-makers to start creating a program to control it. Pooling procedure for MAP culture is an efficient and reliable method. However, the findings suggest the importance of using both ELISA and fecal culture in MAP diagnosis and control.

Keywords: culture, ELISA, IS900 PCR, Johne's disease, Mycobacterium avium subsp paratuberculosis.

\section{Introduction}

Johne's disease (JD) is one of the most wide-spread and economically important disease of ruminants caused by Mycobacterium avium subsp. paratuberculosis (MAP) [1]. Two forms of JD have been described: multibacillary and paucibacillary. The multibacillary, or lepromatous, form is characterized by a granulomatous enteritis by macrophages filled with abundant acid-fast bacteria [2]; the paucibacillary, or tuberculoid, form has diffuse lymphocytic infiltrates in the lamina propria, with few or no visible Mycobacteria [3]. Most cattle are infected early in life by ingestion of MAP through colostrum, milk, fecal contaminated teats,

Copyright: The authors. This article is an open access article licensed under the terms of the Creative Commons Attribution License (http://creativecommons.org/licenses/by/2.0) which permits unrestricted use, distribution and reproduction in any medium, provided the work is properly cited. water, feeds or surfaces. The relatively long incubation period is characterized by the excretion of MAP in feces for months and years before clinical symptoms develop. The exposure to contaminated feces constitutes one of the main risk factors for MAP transmission within the herd [4]. The causative link between MAP and Crohn's disease (CD) is still controversial and the zoonotic potential of MAP still under debate [5]. The definition of an infected animal based either on the presence of anti-MAP antibodies in the serum, or bacterial culture from tissue or feces [6]. No treatment for the disease exists and controlling the disease is difficult due to its long latent period. The use of two to three diagnostic tests has been recommended for herd screening and to increase the accuracy of MAP diagnosis [7]. To date, no vaccine has been developed that elicits an immune response that completely 


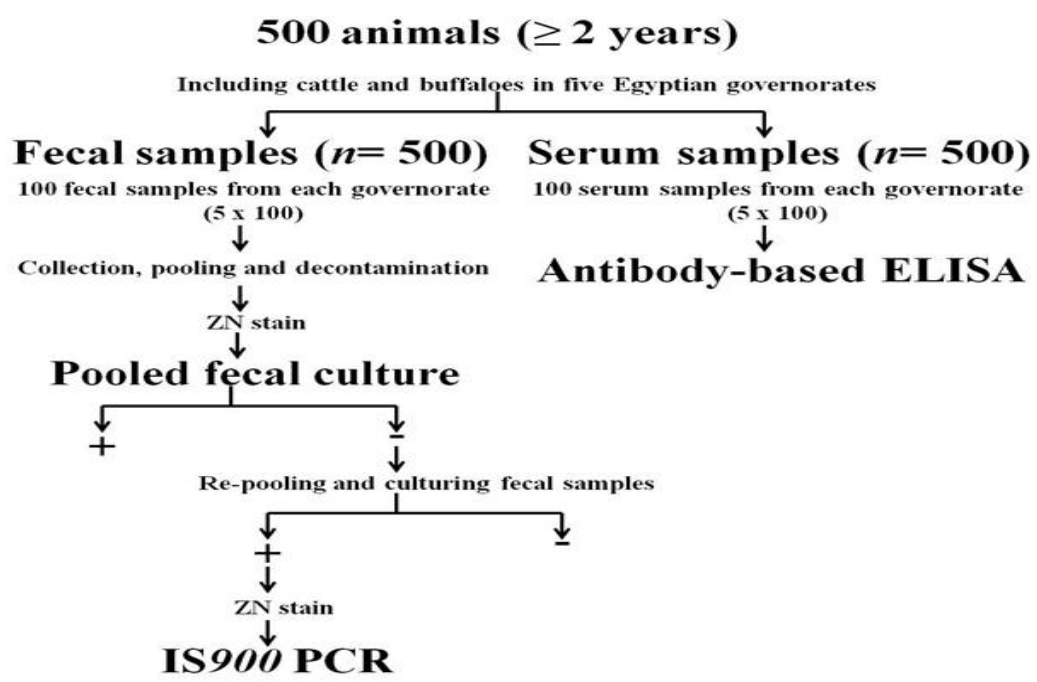

Figure-1: Overview of the study design. Fecal and blood samples were collected from 500 animals (cows and buffaloes) of $\geq 2$ years old present in 5 Governorates throughout Egypt. Fecal samples were decontaminated and examined for MAP on the basis of a strategic pooling procedure. Smears were prepared from decontaminated pellet and after culture from developed colonies, and stained using a ZiehlNeelsen (ZN) technique. The identity of developed colonies was further confirmed by PCR analysis of IS900 sequence. Serum samples of culturepositive and culture-negative animals were evaluated individually for humoral response.

Table-1: The location, the animal spp. and number of fecal and serum samples collected from each spp. Holstein-Friesian cattle and buffaloes housed in five Egyptian governorates were used to collect fecal and serum samples (500 each) and tested in the present study for epizoology of JD in Egypt.

\begin{tabular}{|c|c|c|c|}
\hline Governorate & Animal spp. & No. of fecal samples & No. of serum samples \\
\hline \multirow[t]{2}{*}{ Gharpia } & Cattle & 70 & 70 \\
\hline & Buffaloes & 30 & 30 \\
\hline \multirow[t]{2}{*}{ Menoufia } & Cattle & 60 & 60 \\
\hline & Buffaloes & 40 & 40 \\
\hline \multirow[t]{2}{*}{ Kafr El Sheikh } & Cattle & 50 & 50 \\
\hline & Buffaloes & 50 & 50 \\
\hline \multirow[t]{2}{*}{ Behaira } & Cattle & 80 & 80 \\
\hline & Buffaloes & 20 & 20 \\
\hline \multirow[t]{2}{*}{ Alexandria } & Cattle & 60 & 60 \\
\hline & Buffaloes & 40 & 40 \\
\hline Total & & 500 & 500 \\
\hline
\end{tabular}

eliminates viable MAP from the host (sterile immunity). An effective vaccine which eliminates fecal shedding and prevents clinical disease is the best option for long term control of JD [8].

Multiple studies in many countries have been carried out to determine the prevalence of MAP infections [9]. Although some primary non intensive studies confirm presence of JD in Egypt [10-13], the disease is currently neglected by the official Egyptian veterinary agencies. There is no official data, no national control program, and no used vaccine. Although JD is a notifiable disease in many countries [7], the disease is not a notifiable disease in Egypt. However, it is likely that the prevalence in Egypt will continue to rise to match rates seen elsewhere, unless appropriate preventive and control measures are taken. Owing to that, the focus of scientific research should be addressed to MAP as a livestock pathogen with a potential for human transmission. Further clear investigations are required to determine the likelihood of the current epidemiological situation of infections with MAP in Egypt to make a reliable risk assessment regarding this pathogen. Specific and sensitive diagnostic tools as well as a better understanding of the pathogenesis of JD are needed to develop an effective control program.

This study was aimed to evaluate three conventional diagnostic strategies for MAP under Egyptian circumstances. The tests evaluated include pooled fecal culture, humoral response and IS900 targets PCR and finally, with the general aim to improve information available for selection of a more reliable diagnostic method that can subsequently be considered when developing a JD control program.

\section{Materials and Methods}

Ethical approval: Fecal and serum samples were collected as per standard collection technique.

Study design: The strategy designed to carry out this study is described in Figure-1 and are discussed herein in detail.

Collection of specimens: Fecal and serum specimens (500 for each) were collected from individual adult cows (Holstein-Friesian breed) and buffaloes ( $\geq 2$ years) with and without clinical signs of JD over 2 years $(11 / 2011$ to $08 / 2013)$ from several private farms located in different localities in the following five Egyptian governorates: Gharpia, Menoufia, Kafr El Sheikh, Behaira and Alexandria. Details of fecal and serum samples collected in respect of the location, the animal spp. and number of fecal and serum samples collected from each spp. are summarized in Table-1.

Fecal specimens were collected rectally (using a new plastic disposable sleeve) in sterile labeled plastic container. The specimens were transferred on ice in Styrofoam boxes with minimum of delay to the 
Table-2: Nucleotide sequences of PCR primers (Metabion, Germany). PCR analysis of IS900 sequence was used to identify the developed culture colonies.

\begin{tabular}{lll}
\hline Target gene & Oligonucleotide sequence (5'-3') & Expected amplicon size (bp) \\
\hline Is 900 & F: CCGCTAATTGAGAGATGCGATTGG & 229 \\
& R: AATCAACTCCAGCAGCGCGGCCTCG & \\
\hline
\end{tabular}

Department of Microbiology, Faculty of Veterinary Medicine, Alexandria University. All specimens were stored in a freezer at $80^{\circ} \mathrm{C}$ until utilized for the study. At the same time of fecal specimen collection, blood samples $(10 \mathrm{ml})$ were taken from the same animals from the jugular vein using a sterile needle and $10 \mathrm{ml}$ serum tube.

Pooling, decontamination and bacteriological culture: Fecal samples were examined on the basis of a strategic pooling procedure and $2 \mathrm{~g}$ of each 10 individual fecal specimens was mixed into pooled fecal sample (resulting in a total of 10 pools of 100 individual fecal specimens collected from each governorate). After this, $3 \mathrm{~g}$ of each pool was decontaminated with $0.9 \%(\mathrm{w} / \mathrm{v})$ Hexadecylpyridinium Chloride solution (0.9\% HPC) for $24 \mathrm{~h}$, according to standard procedures [14]. Briefly, $3 \mathrm{~g}$ of feces were added to a $50 \mathrm{~mL}$ sterile falcon tube containing $30 \mathrm{~mL}$ of a $0.9 \%$ HPC. This suspension was manually mixed by shaking and vortexting and let in vertical position for $5 \mathrm{~min}$ at room temperature to allow the precipitation and sedimentation of big particles. Approximately $20 \mathrm{~mL}$ of the upper portion of the supernatant was transferred to another $50 \mathrm{~mL}$ sterile tube in which the whole suspension was agitated for $30 \mathrm{~min}$ by $200 \mathrm{U} / \mathrm{min}$. Tubes were placed in vertical position in the dark for $24 \mathrm{~h}$ at room temperature. Decontaminated pooled fecal samples were centrifuged at $900 \times$ g during $30 \mathrm{~min}$, supernatant was discarded. Smears for Ziehl-Neelsen (ZN) staining were prepared from $100 \mu$ sediment of decontaminated fecal samples and air dried. A $300 \mu \mathrm{L}$ of the decontaminated sediment were cultured using Herrold's Egg Yolk Medium (HEYM) with and without supplementation with mycobactin $\mathrm{J}$ (Prepared Culture Media, Becton Dickinson) [15]. After inoculation, tubes were incubated slanted with the caps lightly screwed at $37^{\circ} \mathrm{C}$. After one week of inoculation slopes were examined for growth of contaminating organisms. After two weeks, the caps were sealed and the tubes were incubated up right. HEYM tubes were observed weekly for 16 weeks, and every month up to six months after for growth [16]. The tubes were being checked for growth of opaque smooth colonies that take on a crumbly appearance as the cultures become older [17]. In case of pools with negative cultures, new pools were prepared from the original fecal specimen and processed for bacteriological diagnosis as previously described.

To provide preliminary identification of mycobacterial isolates, smears were prepared from bacterial colonies, dried in an oven at $65^{\circ} \mathrm{C}$, and stained using a $\mathrm{ZN}$ technique and examined microsco-pically for presence of clumps (three or more organisms) of small (0.5-1.5 $\mu \mathrm{m})$ strongly acid-fast bacilli (AFB) [14].
Humoral immune response determination by indirect ELISA (Ab ELISA): Blood samples without anticoagulant were allowed to clot and the serum was stored at $-20^{\circ} \mathrm{C}$ until required. Serum samples of all culturepositive animals in addition to serum randomly selected from culture-negative animals were evaluated individually for production of antibodies (Ab) against MAP by an indirect ELISA (SERELISA M. ParaTB Ab Mono Indirect ELISA Kit, Synbiotics Corp., Lyon, France). Samples, and test controls were pre-diluted in the sample diluents containing Mycobacterium phlei in order to avoid cross reactions. The reaction technique was carried out according to the manufacturer's instructions. With this kit, optical density (OD) values were transformed to $\mathrm{S} / \mathrm{P}$ ratios based on the OD for the serum sample together with those for the negative and positive controls provided with the kit by using the following equation: $\mathrm{S} / \mathrm{P}$ ratio $=(\mathrm{OD}$ of sample $-\mathrm{OD}$ of negative control)/(OD of positive control - OD of negative control). All assays were run in duplicate. Data are presented as the OD at $405 \mathrm{~nm}\left(\mathrm{OD}_{405}\right)$ for a serum dilution of 1:40.

Molecular MAP confirmation by PCR targeting IS900: DNA extraction from colonies obtained from fecal culture slants of HEYM was carried out using a commercial preparation kit (DNeasy Blood and Tissue Kit, Qiagen, Hilden, Germany). This preparation included overnight lysis buffer incubation at $37^{\circ} \mathrm{C}$, proteinase $\mathrm{K} / \mathrm{AL}$-buffer incubation for $90 \mathrm{~min}$ at $56^{\circ} \mathrm{C}$, and final incubation for $15 \mathrm{~min}$ at $95^{\circ} \mathrm{C}$, as a modification of the protocol of the commercial kit [18]. The PCR was carried out as previously described [19] using primers to detect the presence of MAP-specific IS900 DNA (Table-2). Five $\mu$ l of eluted DNA sample was removed and used as template for amplification in final $25 \mu \mathrm{l}$ of reaction mixture. Additional to the samples, a positive and a negative preparation control, as well as a blank control were included. In the PCR system, a positive MAP control (DNA of a positive MAP strain), a nonMAP negative control (DNA of Mycobacterium bovis), and a master-mix blank control were also included. The amplification product was analyzed using gel electrophoresis on $2 \%$ agarose gel and was subsequently visualized by UV illumination after ethidium bromide staining.

\section{Results}

Isolation of viable mycobacteria by culture: The culture results for all pooled fecal samples tested during this study are shown in Figure-2. MAP was cultured from 34 of the 50 samples tested (68\%). The peak growth index of the positive samples occurred within 12 weeks, but for others, it was as late as 16 


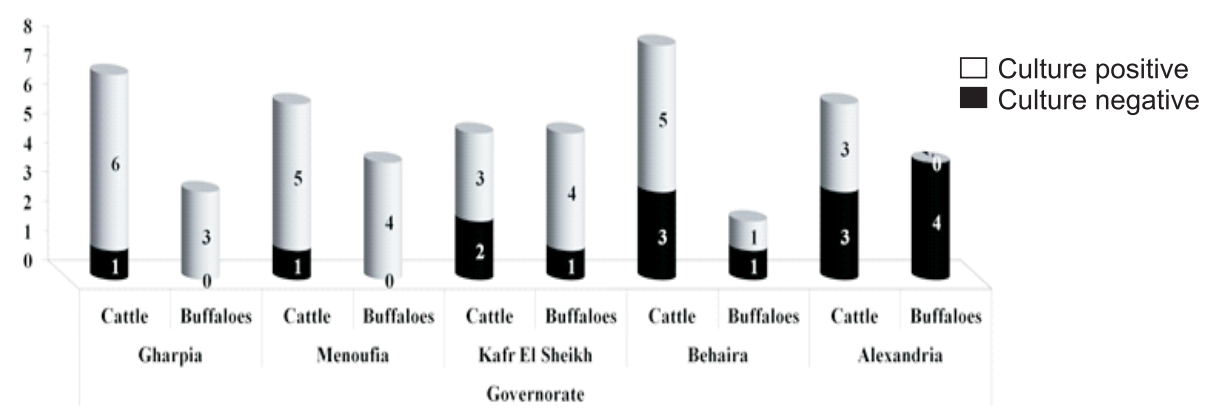

Figure-2: Bacterial culture results on HEYM of pooled fecal samples from cattle and buffaloes present in 5 governorates throughout Egypt. The numbers of positivity in each animal breed of each governorate were indicated.

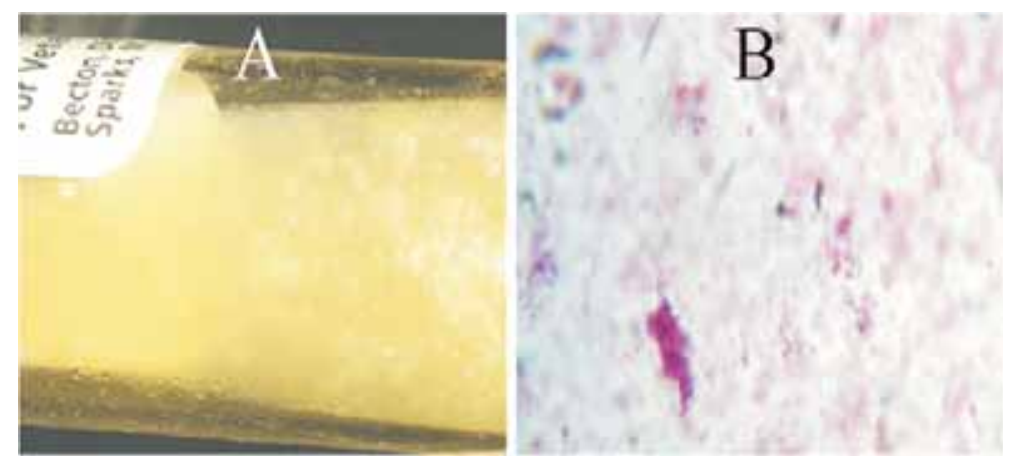

Figure-3: Colonies morphology and microscopic appearance of culture positive pooled fecal samples. A: Smooth colonies of MAP after 10 weeks of culture on a Herrold's egg yolk Medium containing mycobactin J (HEYM) in a sealed tube. B: Microscopic appearance of MAP showing the red acid alcohol-fast ZN staining typical of mycobacterium in bacillary form.

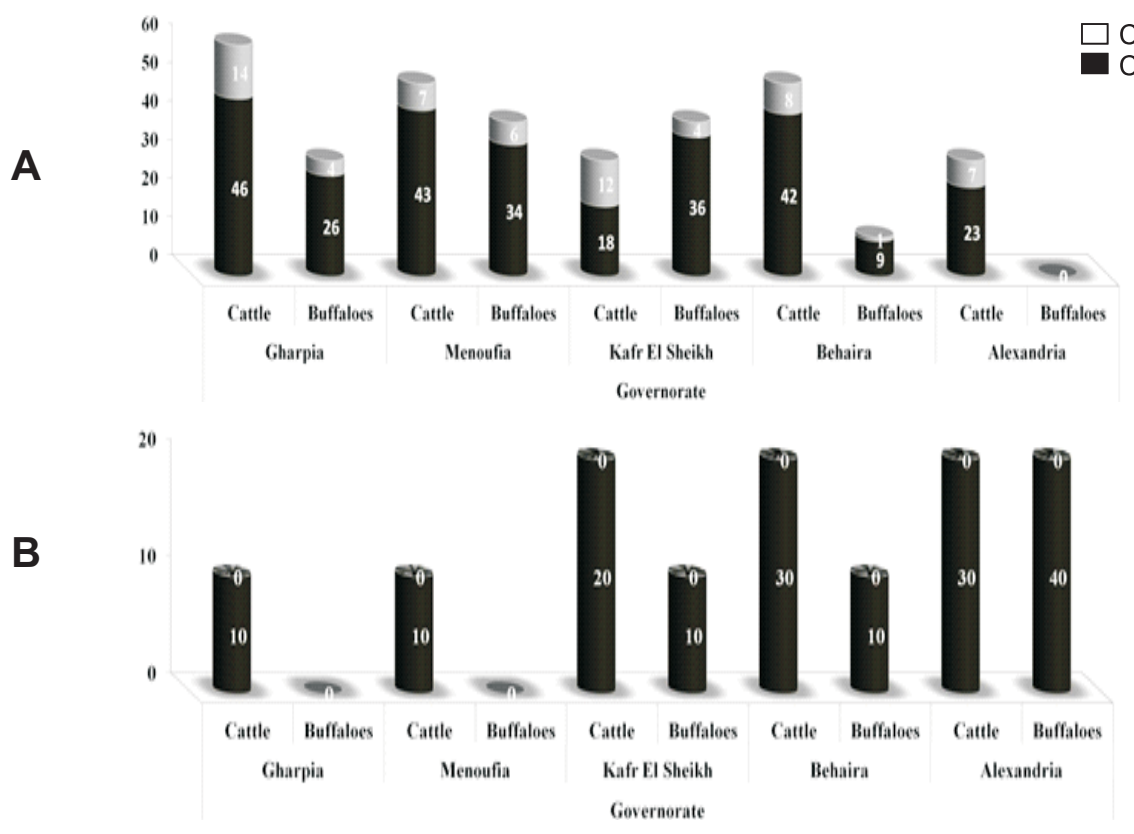

Figure-4: Enzyme-linked immunosorbent assay (ELISA). A: Results of individual serum samples from animals tested positive pooled fecal samples $(n=340)$. B: Results of individual serum samples from animals tested negative pooled fecal samples $(n=160)$. The numbers of positivity in each animal spp. of each governorate were indicated.

weeks. The five Egyptian governorates included were positive. Both cattle and buffaloes were positive with at least one sample positive except pooled fecal samples collected from buffaloes of Alexandria were MAP culture negative even with the second batch. The percentage of MAP positive culture ranged from $50 \%$ to $100 \%$.

Typical smooth colonies of MAP were observed after 10 weeks of culture on a HEYM slope (Figure$3 \mathrm{~A})$. No phenotypic difference was observed between isolates from cattle and buffaloes. Microscopic appearance of MAP showed red acid alcohol-fast ZN staining typical of Mycobacterium in a bacillary form arranged in clumps (Figure-3B).

Serological testing: ELISA was carried out individually to all serum samples of culture-positive animals $(n=340)$ and culture-negative animals $(n=160)$. The ELISA results are shown in Figure-4. In total, out of 340 tested serum samples of culture-positive animals, 63 samples $(18.5 \%)$ were positive sera (Figure-4A). No serum positive were detected in the samples from culture-negative animals (Figure-4 B). 


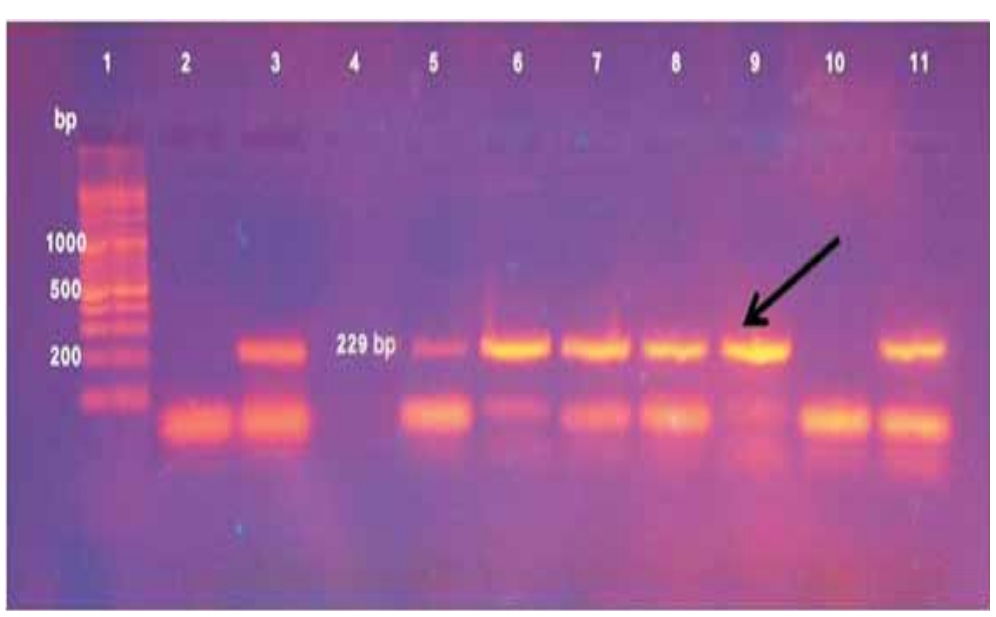

Figure-5: A representative agarose gel with the IS900 specific primers, which generate a fragment that migrates at a molecular weight of $229 \mathrm{bp}$ for the 34 culture-positive pooled fecal samples.

Lane 1: 1000 bp DNA ladder;

Lane 2: Mycobacterium bovis as a negative DNA control;

Lane 3: a standard strain of MAP as a positive control;

Lane 4: a master-mix blank control. Other lanes: Positive (presence of 229 bp amplicons) and negative (absence of 229 bp amplicons) IS900 PCR. Arrow shape: 229 bp amplicons.

Table-3: Overall detection of MAP by culture and IS900 PCR. Out of 50 pooled fecal samples, 34 (68\%) were culture positive of which 18 isolates (52.94\%) were positive for the IS900 PCR. The numbers of positivity in each animal spp. of each governorate were indicated.

\begin{tabular}{lcccr}
\hline Governorate & Animal spp. & No. of pooled fecal samples & Culture-positive N (\%) & IS900 PCR-positive N (\%) \\
\hline Gharpia & Cattle & 7 & $6(85.7)$ & $5(83)$ \\
Menoufia & Buffaloes & 3 & $3(100)$ & $1(33)$ \\
& Cattle & 6 & $5(83)$ & $2(40)$ \\
Kafr El Sheikh & Buffaloes & 4 & $4(100)$ & $1(25)$ \\
& Cattle & 5 & $3(60)$ & $1(33)$ \\
Behaira & Buffaloes & 5 & $4(80)$ & $2(50)$ \\
& Cattle & 8 & $5(62)$ & $0(80)$ \\
Alexandria & Buffaloes & 2 & $1(50)$ & $2(0)$ \\
& Cattle & 6 & $3(50)$ & $0(0)$ \\
& Buffaloes & 4 & $0(0)$ & $18(52.9)$ \\
\hline
\end{tabular}

IS900 PCR: The PCR results on the colonies extract DNA of culture-positive pooled fecal samples are shown in Figure-5 and summarized in Table-3. The PCR results represented as number and percent positive samples. In total, out of 34 tested isolates, 18 isolates (52.94\%) were positive for the IS900 PCR.

The five Egyptian governorates included were positive. Both colonies of cattle and buffaloes were positive for IS900 with at least one sample positive except colonies of buffaloes of Behaira were negative. The percentage of positive samples varied from $25 \%$ to $83 \%$.

\section{Discussion}

The diagnostic tests available for JD either detect MAP itself or the host's immune response to it [20]. Diagnosis in animals displaying clinical signs is easily accomplished. However, screening subclinically infected animals that represent the majority of infected animals in a herd for MAP infection is fraught with difficulties using the tests that are currently available [21]. Fecal culture and ELISA have been the most common MAP diagnostic methods [7].

Bacteriological culture of MAP is considered the gold standard of diagnosis for infection [22]. Although tissue culture, particularly ileo-cecal lymph node culture, is generally considered to be more sensitive, fecal culture is the more practical mean of confirming infection in herd screening programs. Although fecal culture is technically difficult and time-consuming [23], it is the only test that does not produce falsepositive results (100\% specificity) for the live animal and a useful tool in abating the spread of disease [20]. Thus, a single positive fecal culture provides definitive proof of MAP infection. However, a single negative fecal culture does not definitively classify an animal as non-infected.

One way to overcome the high costs of fecal culture is to pool fecal samples of individual animals. Although, pooling of samples could be a cost-effective way to test a herd for a disease [24], the sensitivity of this method is variable. An advantage of pooled testing over testing individuals is that more individuals can be represented in pooled tests for the same fixed laboratory costs. Several studies have indicated that pooling feces from herds that contain heavy shedders or have a high prevalence herds is equivalent in sensitivity to culturing individual animals. However, pooling feces from herds with low or moderate shedders or in low prevalence herds may fail to detect the organism [25]. The egg-based media (LJM and HEYM) are the first choice for the culture of clinical and environmental samples [26]. The primary goal of the present study was to evaluate the current conventional diagnostic methods for MAP under Egyptian circumstances. The first evaluated test was the pooled fecal culture. Fecal samples were examined for MAP on the basis of a strategic pooling procedure and performed on HEYM. MAP was cultured from 34 (68\%) of the tested samples from all included Egyptian governorates with the positive percentage ranged from $50 \%$ to $100 \%$ (Figure2). Typical MAP colonies from cattle and buffaloes were developed without any phenotypic difference (Figure-3 A and B). According to our results, the 
epizoology of MAP is suggested to be similar in both Egyptian cattle and buffaloes. To our knowledge, this is the first study documented the JD in Egyptian buffaloes. Buffaloes are important domestic animals for milk and meat production and contribute significantly to the agricultural economy. The total numbers of cows and buffaloes in Egypt are 4.9 and 4.1 million respectively. Most of these ruminants are often reared side by side in rural areas where they share the same pasture and the same shelter. These facts should be considered before starting a JD control program.

The facts of bacterial growth is slow with test results being available only after months of incubation, and shedding of MAP at detectable levels in feces is irregular, lead to considering immune-based diagnostic tests are relevant alternatives to fecal culture [27]. The sensitivity of the ELISA for the detection of serum antibodies to MAP in individual cows has been evaluated extensively. Despite of low sensitivity and specificity, ELISA is considered a method of choice for the detection of JD positive herds. This is due to the suitability of samples collection, rapid laboratory turnaround time, low cost, and possibility to test a large number of samples in a short time [7]. The second evaluated test in the current study was the humoral response method. Serum samples of all culture-positive animals in addition to serum randomly selected from culture-negative animals were evaluated individually for humoral response. Serum positive samples of culture-positive animals were 63/340 (18.5\%). Current evidence indicates that ELISA sensitivity is highly dependent on the stage of MAP infection (stage I: preclinical, not shedding bacteria in feces; stage II: preclinical, shedding bacteria in feces; or stage III: clinical, shedding bacteria in feces) [28]. The ELISA has a sensitivity rising from almost zero at the early stages of the disease up to $75 \%$ when the animal reaches the clinical stage. In whole-herd testing, sensitivity of serologic assays for JD is less $50 \%$ when compared to fecal culture [29]. In the present study, all individual animals with MAP-positive serum were within categories of animals positive for pooled fecal cultures. However, we couldn't determine the true sensitivity of ELISA relative to culture-positive pooled fecal samples because it is not possible to determine which animal is MAP infected except by re-culturing individually the fecal samples of each pool. Fortunately, the ELISA positive results within animals with culture positive maximize the efficiency of this test.

On the contrary, No serum positive were detected in the samples from culture-negative animals. This means the specificity of the ELISA test relative to fecal culture was $100 \%$ and this is for the assumption that the negative results of the culture had no false negative. Several characteristics of MAP and its resultant infection make false negative fecal culture results possible. The chronic nature of MAP infection results in a delay between the time of the initial infection and fecal shedding of the agent which may be intermittent or involving small numbers of MAP, particularly early in the course of the infection [28]. The fastidious nature and potential for variations in growth requirements between MAP strains may preclude culture. So it's not fair to determine the efficiency of ELISA depending on the results of culture. These findings would suggest the importance of using both ELISA and fecal culture in diagnosis and control of JD.

Although there is a wide range of molecular techniques available for the identification of MAP isolates, the selection of the most appropriate tool greatly depends on the purpose, facilities and expertise of the veterinary and public health laboratories [30]. PCR targeting specific multi-copy elements such as IS900 appear to be an excellent choice in order to achieve high sensitivity in the identification of MAP [31]. Typically an IS900 PCR assay is applied to fresh isolates, broth cultures or milk and if positive and coupled with mycobactin dependency, the isolate is deemed to be MAP [30].

The third evaluated test of this study was the IS900 targets PCR for molecular MAP confirmation. In the present study, 18 isolates (52.94\%) were positive for the IS 900 PCR with the positive percentages varied from $25 \%$ to $83 \%$. The low percentages could be explained by the probability that the positive cultures / negative IS900 PCR-animals were mixed cultures, i.e., contained Mycobacterium spp. other than MAP. One reason of this suggestion is that not all individual animals with MAP-positive serum were positive for the IS900 PCR (data not shown). In a previous study [32], 5\% of AFB-positive cultures were IS900 PCR negative, suggesting that other Mycobacteria were present. Because of limited resources, PCR panel of primers used for identification of members of the Mycobacterium avium complex and subsequent sequence analysis were not carried out in the current study to verify whether there are other types of environmental Mycobacteria. Further genotypic investigations study for the strain diversity of MAP isolates and speciation of non-MAP isolates will be our next task.

\section{Conclusion}

In conclusion, the present study succeeded to isolate and identify MAP from Egyptian cattle and buffaloes in five governorates. The results confirm the epizoology of JD in Egypt and encourage the decisionmakers to start creating a program to control it. Pooling procedure for MAP culture is an efficient and reliable method. However, the findings suggest the importance of using both ELISA and fecal culture in MAP diagnosis and control.

\section{Authors' contributions}

The present study is a part of the research project. GSA conceived the research theme and designed methods. GSA and AEG collected the fecal and serum samples, implemented the bacterial culture and PCR. MME and GSA carried out the ELISA test. GSA, MME and AEG 
analyzed the data, interpreted the results. SAK codesigned experiments, discussed analyses, interpretation, and presentation. GSA, MME and AEG drafted the manuscript. GSA revised the manuscript. All authors read and approved the manuscript.

\section{Acknowledgments}

The authors gratefully acknowledge Prof. Dr. William Davis (Bill Davis) and Dr. Kun Take Park; WSU, Pullman, WA, USA for the scientific support. This project was funded by Science and Technology Development Fund (STDF), basic and applied, under Contract No. 2081 and Research Enhancement Program (ALEX REP), Alexandria University Research Fund (AURF).

\section{Competing interests}

The authors declare that they have no competing interests.

\section{References}

1. Office International Des Epizooties (OIE) (2013) Manual of Diagnostic Tests and Vaccines for Terrestrial Animals (mammals, birds and bees). Volume 1. Paris, France, 1-12. http://www.oie.int/fileadmin/Home/eng/Health standards/t ahm/1.01.01_COLLECTION_DIAG_SPECIMENS.pdf. Accessed on 09-09-2013.

2. Clarke C.J. and Little D. (1996) The pathology of ovine paratuberculosis: gross and histological changes in the intestine and other tissues. J. Comp. Pathol. 114:419-437.

3. Clarke, C.J. (1997) Paratuberculosis and molecular biology. The Vet. J. 153(3): 245-247.

4. Whittington, R.J., Marsh, I.B. and Whitlock, R.H. (2001) Typing of IS 1311 polymorphisms confirms that bison (Bison bison) with paratuberculosis in Montana are infected with a strain of Mycobacterium avium subsp. paratuberculosis distinct from that occurring in cattle and other domesticated livestock. Mol. Cell. Probes. 15(3): 139-145.

5. Koc,A., Bargen,I., Suwandi,A., Roderfeld,M., Tschuschner, A., Rath,T., Gerlach,G.F., Hornef,M., Goethe,R., Weiss,S. and Roeb,E. (2014) Systemic and Mucosal Immune Reactivity upon Mycobacterium avium ssp. paratuberculosis Infection in Mice. PLos. One. 9(4): e94624.

6. Minozzi,G., Williams,J.L., Stella,A., Strozzi,F., Luini,M. Settles,M.L., Taylor,J.F., Whitlock,R.H., Zanella,R. and Neibergs,H.L. (2012) Meta-Analysis of Two Genome-Wide Association Studies of Bovine Paratuberculosis. PLos. One, 7(3): e 32578.

7. Collins,M.T. (2011) Johne's Disease, an Issue of Veterinary Clinics: Food Animal Practice. Elsevier Health Sciences.

8. Hines,M.E., Turnquist,S.E., Ilha,M.R., Rajeev,S., Jones,A.L., Whittington,L., Bannantine,J.P., Barletta,R.G., Grohn,Y.T., Katani,R., Talaat,A.M., Li,L. and Kapur,V. (2014) Evaluation of novel oral vaccine candidates and validation of a caprine model of Johne's disease. Front. Cell. Infect. Microbiol. 4: 26.

9. Okura,H., Toft,N. and Nielsen,S.S. (2012) Occurrence of Mycobacterium avium subsp. paratuberculosis in milk at dairy cattle farms: A systematic review and meta-analysis. Vet. Microbiol. 157(3-4): 253-263.

10. Abd El-Malek and S.A. and Mohamed K.F. (2011) Phylogenetic Analysis of Mycobacterium avium subsp. paratuberculosis of Some Egyptian Isolates Isolated from Clinically Infected Dairy Cattle. Int. J. Microbiol. Res. 2(1): 49-53.

11. Badr, H.M. (2011) Inactivation of Mycobacterium paratuberculosis and Mycobacterium tuberculosis in fresh soft cheese by gamma radiation. Radiat. Phys. Chem. 80(11): 1250-1257.

12. El Sayed, A., Hassan, A. A., Natour, S., Abdulmawjood, A.,
Bulte, M., Wolter, W. and Zschock, M. (2009) Evaluation of three molecular methods of repetitive element loci for differentiation of Mycobacterium avium subsp. paratuberculosis (MAP). J. Microbiol.47:253-259.

13. Salem, M., Zeid, A. A., Hassan, D., El Sayed, A. and Zschoeck, M. (2005) Studies on Johne's disease in Egyptian cattle.J. Vet. Med. 52:134-137.

14. Office International Des Epizooties (OIE) (2008) Paratuberculosis (Johne's disease).Terrestrial Manual Chapter 2.1.11. http://www.oie.int/fileadmin/Home/eng/Health_standards/t ahm/2.01.11 PARATB.pdf. Accessed on 09-09-2013.

15. Florou, M., Leontides, L., Kostoulas, P., Billinis, C., Sofia, M., Kyriazakis, I. and Lykotrafitis, F. (2008) Isolation of Mycobacterium avium subspecies paratuberculosis from non-ruminant wildlife living in the sheds and on the pastures of Greek sheep and goats. Epidemiol. Infect. 136: 644-652.

16. Allen,A.J., Park,K.T., Barrington,G.M., Lahmers,K.K., Abdellrazeq,G.S., Rihan,H.M., Sreevatsan,S., Davies,C., Hamilton,M.J. and Davis,W.C. (2011) Experimental infection of a bovine model with human isolates of Mycobacterium avium subsp. paratuberculosis. Vet. Immunol. Immunopathol. 141(3-4): 258-266.

17. World Health Organization (2004) Pathogenic Mycobacteria in Water: A Guide to Public Health Consequences, Monitoring and Management. Edited by S. Pedley, J. Bartram, G. Rees, A. Dufour and J. Cotruvo. ISBN: 184339 059 0. Published by IWA Publishing, London, UK. http://www.bvsde.paho.org/CD-GDWQ/Biblioteca/ Support $\% 20$ docs\%20GDWQ/patmycrobact.pdf.Accessed on 5-10-2013.

18. Fernandez-Silva,J.A., Abdulmawjood,A. and Bulte,M. (2011) Diagnosis and Molecular Characterization of Mycobacterium avium subsp. paratuberculosis from Dairy Cows in Colombia. Vet. Med. Int. 352561.

19. Park,K.T., Allen,A.J., Bannantine,J.P., Seo,K.S., Hamilton, M.J., Abdellrazeq,G.S., Rihan,H.M., Grimm,A. and Davis, W.C. (2011) Evaluation of two mutants of Mycobacterium avium subsp. paratuberculosis as candidates for a live attenuated vaccine for Johne's disease. Vaccine. 29(29-30): 4709-4719.

20. Timms,V.J., Gehringer,M.M., Mitchell,H.M., Daskalopoulos, G. and Neilan,B.A. (2011) How accurately can we detect Mycobacterium avium subsp. paratuberculosis infection? J. Microbiol. Meth. 85(1): 1-8.

21. Aly, S. S., Anderson, R. J., Whitlock, R. H., Fyock, T. L., McAdams, S. C., Byrem, T. M., Jiang, J., Adaska, J. M. and Gardner, I. A. (2012) Cost-effectiveness of diagnostic strategies to identify Mycobacterium avium subspecies paratuberculosis super-shedder cows in a large dairy herd using antibody enzyme-linked immunosorbent assays, quantitative real-time polymerase chain reaction, and bacterial culture. J. Vet. Diagn. Investig. 24: 821-832.

22. Martinson S.A., Hanna P.E., Ikede B.O., Lewis J.P., Miller L.M., Keefe G.P. and McKenna S.L.B. (2008) Comparison of bacterial culture, histopathology and immunohistochemistry for the diagnosis of Johne's disease in culled dairy cows. J. Vet. Diagn. Investig. 20, 51-57.

23. Van, S.G., Stehman, S.M., Schukken, Y.H., Rossiter, C.R. and Shin, S.J. (2003) Pooled fecal culture sampling for Mycobacterium avium subsp. paratuberculosis at different herd sizes and prevalence. J. Vet. Diagn. Investig. 15(3): 233241.

24. Gardner,I.A., Nielsen,S.S., Whittington,R.J., Collins,M.T., Bakker,D., Harris,B., Sreevatsan,S., Lombard,J.E., Sweeney,R., Smith,D.R., Gavalchin,J. nd Eda,S. (2011) Consensus-based reporting standards for diagnostic test accuracy studies for paratuberculosis in ruminants. Prev. Vet. Med. 101(1-2): 18-34.

25. Logar K, Kopinc R, Bandelj P, Staric J, Lapanje A. and . (2012) Evaluation of combined high-efficiency DNA extraction and real-time PCR for detection of Mycobacterium avium subsp. paratuberculosis in subclinically infected 
dairy cattle: comparison with faecal culture, milk real-time PCR and milk ELISA. BMC Vet. Res. 8: 49.

26. Moravkova, M., Babak, V., Kralova, A., Pavlik, I. and Slana, I. (2012) Culture- and Quantitative IS900 Real-Time PCRBased Analysis of the Persistence of Mycobacterium avium subsp. paratuberculosis in a Controlled Dairy Cow Farm Environment. Appl. Environ. Microbiol. 78: 6608-6614.

27. Mikkelsen,H., Aagaard,C., Nielsen,S.S. and Jungersen,G. (2011) Review of Mycobacterium avium subsp. paratuberculosis antigen candidates with diagnostic potential. Vet. Microbiol. 152(1-2): 1-20.

28. Nielsen,S.S. and Toft,N. (2008) Ante mortem diagnosis of paratuberculosis: a review of accuracies of ELISA, interferon-gamma assay and faecal culture techniques. Vet. Microbiol. 129(3-4): 217-235.

29. Singh, P.K., Singh, S.V., Kumar, H., Sohal, J.S. and Singh, A. V. (2010) Diagnostic Application of IS900 PCR Using Blood as a Source Sample for the Detection of Mycobacterium avium Subspecies Paratuberculosis in Early and Subclinical Cases of Caprine Paratuberculosis. Vet. Med. Int. 2010: 748621.

30. Castellanos, E., de Juan, L., Domínguez, L. and Aranaz, A. (2012) Progress in molecular typing of Mycobacterium avium subspecies paratuberculosis. Res. Vet. Sci.92(2): 169-179.

31. Green, E. P., M. L. Tizard, M. T. Moss, J. Thompson, D. J. Winterbourne, J. J. McFadden, and J. Hermon-Taylor. (1989) Sequence and characteristics of IS900, an insertion element identified in a human Crohn's disease isolate of Mycobacterium paratuberculosis. Nucleic Acids Res. 17: 9063-73.

32. Kim, S.G., Kim, E.H., Lafferty, C.J., Miller, L.J., Koo, H.J., Stehman, S.M. and Shin, S.J. (2004) Use of conventional and real-time polymerase chain reaction for confirmation of Mycobacterium avium subsp. paratuberculosis in a brothbased culture system ESP II. J. Vet. Diagn. Investig. 16(5): 448-453.

$* * * * * * * *$ 